\title{
Evaluation of middle ear pressure and post-operative adenoid size in adenotonsillectomy: comparison between curettage and endoscopic assisted coblation technique
}

\author{
Sweekritha N. Bhat, Angshuman Dutta*
}

Department of ENT, Command Hospital Air Force, Bangalore, Karnataka, India

Received: 17 December 2018

Revised: 04 February 2019

Accepted: 06 February 2019

\section{*Correspondence:}

Dr. Angshuman Dutta,

E-mail: duttaangshuman@ rediffmail.com

Copyright: ( ) the author(s), publisher and licensee Medip Academy. This is an open-access article distributed under the terms of the Creative Commons Attribution Non-Commercial License, which permits unrestricted non-commercial use, distribution, and reproduction in any medium, provided the original work is properly cited.

\begin{abstract}
Background: The aim of the study is to evaluate the effect on middle ear pressure and study the residual adenoid size post adenotonsillectomy after adenotonsillectomy by curettage and endoscopic assisted coblation among pediatric age group.

Methods: The present study was designed as a prospective observational study among patients undergoing adenotonsillectomy in a tertiary care hospital among pediatric age group (7-13 years) by measuring middle ear pressure (by tympanometry) and residual adenoids post adenoidectomy by diagnostic nasal endoscopy in 60 patients. The patients were included by simple random sampling, 30 patients for each group one undergoing cold steel the other endoscopic coblation adenotonsillectomy.

Results: Greater reduction was observed in the post-operative adenoid size with endoscopic assisted coblation as compared to curettage. The difference in the middle ear pressure at pre operatively, day 1, day 7 and at 3 months between the study groups was not statistically significant.

Conclusions: In our study endoscopic coblation technique was found to be more superior to curettage in terms of greater reduction in adenoid mass. The effects on transient middle ear pressure between both study groups showed no difference.
\end{abstract}

Keywords: Adenotonsillectomy, Coblation, Endoscope, Tympanometry

\section{INTRODUCTION}

Adenoidectomy and tonsillectomy has been one of the majorly common surgical procedures in the pediatric age group. Tonsillar and adenoid hypertrophy has been known to cause breathing problems like obstructive sleep apnoea, neurocognitive delay and impacting the overall quality of life of the child. ${ }^{1}$ Coblation is a controlled, non-heat driven process using radiofrequency energy which excites the electrolytes in a conductive medium (saline) solution, and thereby creating a precisely focused plasma field. The function of this energy field is to break molecular bonds within tissue, causing dissolution of tissues at lower temperatures (typically $40^{\circ} \mathrm{C}$ to $70^{\circ} \mathrm{C}$ ) leading to removal of target tissue with minimal damage. These devices are also designed to achieve hemostasis by coagulation of bleeding vessels. Tissue heating is minimal as the radiofrequency current is not passed directly through tissue. ${ }^{2}$

The problems with curettage adenoidectomy is that greater amount of residual adenoid remains post-surgery and requires more operative time. These difficulties are overcome with endoscopic coblation adenoidectomy. The 
main advantages of endoscopic adenoidectomy are the improved visualisation and magnification, superior haemostasis, complete removal of adenoid tissue, reduction of unnecessary trauma and improved safety. ${ }^{3}$

Negative pressure changes in the middle ear are observed due to edema in the nasopharynx following tonsillectomy but there aren't many studies to prove the same. ${ }^{4,5}$ Tympanometry is indirectly used to determine the middle ear pressure changes - both pre operatively and post operatively. Though endoscopic assisted coblation technique of tonsillectomy and adenoidectomy is superior to curettage there is a paucity of literature to assess the effectiveness in measuring residual adenoid size and evaluate middle ear pressure by tympanometry which was carried out in our study.

\section{METHODS}

A prospective, observational study to compare adenotonsillectomy by curettage and endoscopic assisted coblation among pediatric age group 7-13 years by measuring middle ear pressure by tympanometry and residual adenoids post adenoidectomy by diagnostic nasal endoscopy.

Study place: Command Hospital Air Force Bangalore.

Study duration: 2 years period between October 2016 to October 2018.

Sampling technique: Simple random sampling, 30 patients for each group. Coblation and curettage group.

Tympanometry was used to determine the middle ear pressure changes both pre operatively and post operatively. Commonly used is the AZ 26, Interacousics, Denmark. It is performed with the patient in a sitting position in the morning one day before the day of the operation. Tympanogram curve was identified by 3 main features: shape of the curve (presence of any peaks), pressure of the peak point and amplitude of the peak Follow up tympanometry was done on postoperative day 1, day 7 and at 3months.All patients had type $\mathrm{A}$ tympanogram preoperatively.

Nasal endoscopy was done using a pediatric flexible rhinopharyngoscope. Endoscopic grading of adenoids was done using grading of amount of choanal obstruction by the adenoids given by Clemen's ${ }^{6}$.The following system of adenoid classification is commonly used :

Grade 1: Adenoid occupying less than $25 \%$ of the choanal area.

Grade 2: Adenoid occupying 25-50\% of the choanal area.

Grade 3: Adenoid occupying 50-75\% of the choanal area.

Grade 4: Adenoid occupying 75-100\% of the choanal area.

\section{Statistical tools}

Middle ear pressure and residual adenoids post adenoidectomy (DNE) were considered as outcome variables. Intervention group (curettage and endoscopy assisted coblation) were considered as explanatory variable. The quantitative parameters were checked for normal distribution within each study group by ShapiroWilk's test $(p>0.05) 1,2$, visual inspection of their histograms, normal Q-Q plots and box plots. Skewness and Kurtosis Z- values ( $\mathrm{Z}$-value between -1.96 to +1.96 was considered as normal distribution) were also assessed.

The non-normally distributed quantitative variable (middle ear pressure) compared between the two groups using Mann Whitney U test (Median IQR). Categorical variables were compared between two groups using Chisquare test $\mathrm{p}<0.05$ was considered statistically significant.

IBM SPSS version 22 was used for statistical analysis.

\section{RESULTS}

In the curettage group, $17(56.7 \%)$ were male and 13 $(43.3 \%)$ were female. Among the people with endoscopy assisted coblation, $14(46.7 \%)$ participants were males and $16(53.3 \%)$ were females, the difference in the proportion of gender between study groupwas statistically not significant $(\mathrm{p}=0.438)$.

Among the people with curettage, the median age was 10 (Interquartile range IQR 8 to 12 ) and it was 10 (IQR 8 to 11.25) in people with endoscopy assisted coblation. The difference in the age between study group was statistically not significant $(\mathrm{p}=0.687)$.

Table 1: Comparison of pre and postoperative diagnostic nasal endoscopy between two study groups $(n=60)$.

\begin{tabular}{|lll|}
\hline DNE & $\begin{array}{l}\text { Study group } \\
\text { Curettage }\end{array}$ & $\begin{array}{l}\text { Endoscopy assisted } \\
\text { coblation }(\mathbf{n}=\mathbf{3 0})\end{array}$ \\
\hline \multicolumn{3}{|c|}{$\mathbf{N}(\%)$} \\
$\mathbf{N}(\%)$ \\
\hline Adenoid size preoperative \\
\hline Grade I & $2(6.7)$ & $0(0)$ \\
\hline Grade II & $11(36.7)$ & $14(46.7)$ \\
\hline Grade III & $13(43.3)$ & $12(40)$ \\
\hline Grade IV & $4(13.3)$ & $4(13.3)$ \\
\hline $\begin{array}{l}\text { Diagnostic nasal endoscopy adenoid size 3 months } \\
\text { post operative }\end{array}$ & $4(13.3)$ \\
\hline Grade I & $9(30)$ & $4(13.3)$ \\
\hline Grade II & $8(26.7)$ & $1(3.3)$ \\
\hline Grade III & $0(0)$ & $21(70)$ \\
\hline Nil & $13(43.3)$ & 0 \\
\hline
\end{tabular}

*No statistical test was applied due to 0 subjects in one of the cells. 


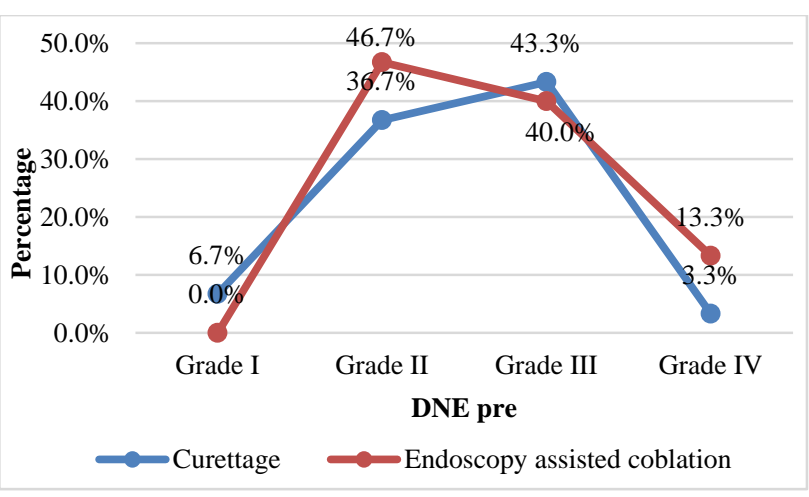

Figure 1: Line diagram of comparison of pre operative diagnostic nasal endoscopy between two study groups $(n=60)$.

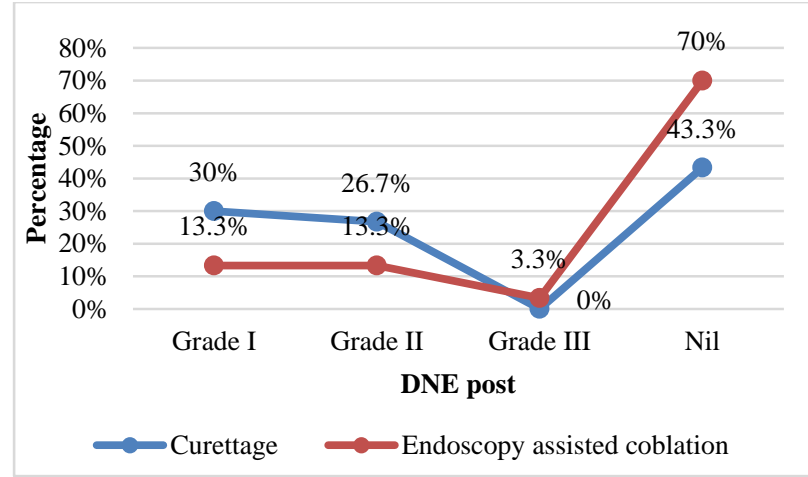

Figure 2: Line diagram of comparison of postoperative diagnostic nasal endoscopy between two study groups $(n=60)$.

Table 2: Comparison of pre and postoperative middle ear pressure in intervention groups $(\mathbf{n}=60)$.

\begin{tabular}{|llll|}
\hline Middle ear pressure & $\begin{array}{l}\text { Study group } \\
\text { Curettage } \\
\text { (Median IQR) }\end{array}$ & $\begin{array}{l}\text { Endoscopy assisted coblation } \\
\text { (Median IQR interquartile } \\
\text { range) }\end{array}$ & $\begin{array}{l}\text { Mann Whitney } \\
\text { U test } \\
\text { P value }\end{array}$ \\
\hline Middle ear pressure base line & $127.50(120$ to 135$)$ & $130(127.25$ to 136.75$)$ & 0.166 \\
\hline Middle ear pressure post op day 1 & $121.50(115.25$ to 129.25$)$ & $121.50(113.75$ to 125.5$)$ & 0.579 \\
\hline Middle ear pressure post op day 7 & $116(111$ to 123$)$ & $119(113.75$ to 124.25$)$ & 0.273 \\
\hline Middle ear pressure at 3months & $115(109.75$ to 123.50$)$ & $111.50(105.75$ to 127.50$)$ & 0.519 \\
\hline
\end{tabular}

As per Table 2 the difference in the middle ear pressure baseline between study groups at baseline, on postoperative day 1 , on post-operative day 7 and at 3 months between study groups was statistically not significant.

\section{DISCUSSION}

The present study was designed as a prospective observational study among patients undergoing adenotonsillectomy in a tertiary care hospital with the aim of comparing curettage and endoscopic assisted coblation among paediatric age group by measuring middle ear pressure (by tympanometry), residual adenoids post adenoidectomy (by diagnostic nasal endoscopy). 60 patients in the age group 7-13 years were included by simple random sampling, 30 patients for each group.

In the (Table 1) curettage group, $2(6.7 \%)$ patients had grade I, $11(36.7 \%)$ patients had grade II, $13(43.3 \%)$ patients had grade III and $4(13.3 \%)$ patients had grade IV adenoids preoperatively. In the endoscopy assisted coblation group, 14 (46.7\%) had grade II, 12 (40\%) had grade III and $4(13.3 \%)$ had grade IV adenoids preoperatively. In the curettage group, postoperative adenoid grading was $9(30 \%)$ patients had grade I, 8 (26.7\%) patients had grade II, and $13(43.3 \%)$ people had nil. In the endoscopy assisted coblation group, 4 (13.3\%) patients had grade I, 4 (13.3\%) patients had grade II, 1 $(3.3 \%)$ people had grade III and $21(70 \%)$ people had nil. In our study greater reduction was observed in the postoperative adenoid size with endoscopic assistance as compared to curettage though no statistical test of significance could be applied.

A prospective double blinded randomised trial was undertaken by Murat et al studying endoscopic assisted technique versus curettage adenoidectomy. ${ }^{7}$ It was seen that a statistically significant difference in mean ratio (Adenoid pad nasopharyngeal space ratio on CT scan) of 0.41 curettage and 0.30 in endoscopic group was found. There was no statistically significant difference between the two groups in regard to improvement of symptoms. The objective outcomes showed endoscopic-assisted adenoidectomy technique was superior to curettage adenoidectomy in reducing adenoidal size post-surgery. Businco et al in their study of 40 children found a higher persistence of adenoid as seen by endoscopy in the group that underwent curettage. ${ }^{8}$ Endoscopic coblation adenoidectomy ensured the complete removal of adenoids and reduced postoperative adenoid remnant. The authors found it safer under endoscopic control and easier access to the cranial portion of the adenoid and its intranasal extension. ${ }^{3}$ Coblation adenoidectomy was able to reach all areas of nasopharynx upto eustachian tube opening and allows selective and precise ablation of adenoid tissue. In our study greater reduction was observed in the postoperative adenoid size with endoscopic assistance as compared to curettage.

Ozturk et al in a study of 53 patients found a greater reduction in adenoid size as seen in power assisted 
endoscopic adenoidectomy than curettage adenoidectomy ( $p<0.0001)$. In our study also it was seen that endoscopic coblation adenoidectomy was more effective in reducing adenoid size to a greater extent. El Tahan et al in a study of 200 children found that the patients who underwent curettage adenoidectomy group had reduced recurrence of adenoid mass. The incidence of postoperative regrowth of adenoid tissue was higher in conventional cold curette adenoidectomy group than in the coblation group. ${ }^{10}$ The coblation wand facilitated the precise removal of the adenoid remnants and helped in approaching the difficult to reach areas such as posterior choanae and around eustachian tube opening which are the commonest sites of recurrent adenoid hypertrophy leading to reduced recurrence. Feng et al conducted a retrospective study to compare power assisted adenoidectomy with adenoid curette adenoidectomy with regard to the cross-sectional area of adenoids following surgery. ${ }^{11}$ They found a significant improvement $(\mathrm{p}<0.01)$ in the cross sectional area at the nasopharyngeal area in the coblation group by acoustic rhinometry.

Regmi et al conducted a cross sectional study in 41 children to assess the effectiveness of curettage adenoidectomy and to evaluate the role of endoscopy in improving the results of curettage adenoidectomy. ${ }^{3}$ The results showed that rigid curettage alone was not enough to completely remove the adenoid tissue in all patients and residual tissue remained in anterior vault, and to a lesser extent in choanae (in 67.2 per cent of patients). Post this when endoscopic assisted curettage was done, it successfully helped in removing the residual adenoid tissue (with the exception of 2 cases). The mean volume of adenoid tissue that was removed via conventional curettage was $1.74 \pm 0.77 \mathrm{ml}$ (range 0.50-3). An additional tissue $0.91 \pm 0.34 \mathrm{ml}$ (range $0.5-2$ ) was removed in endoscopic assisted adenoidectomy. They concluded that use of endoscope enabled removal of $34.3 \%$ of total adenoid volume. Bradoo et al conducted a prospective randomized study among 32 patients with a mean age of 8.3 years to study the outcomes of conventional adenoidectomy procedure and endoscope-assisted adenoidectomy. ${ }^{12}$ The results showed an increased incidence of residual adenoid tissue 3 months post surgery in the curettage adenoidectomy group as compared to the endoscopic group $(\mathrm{p}<0.05)$.

Thiagarajan et al in their study of 40 children assessed the amount of residual adenoid tissue by performing nasal endoscopy using $2.7 \mathrm{~mm} 0$ degree nasal endoscope. ${ }^{13}$ The amount of residual adenoid tissue was higher in conventional adenoidectomy as compared to those who had undergone coblation technique and this difference was significant. Similar results were found in our study. Goel et al in a study of 54 pediatric patients compared the efficacy of conventional adenoidectomy with endoscope assisted methods. ${ }^{14}$ The results showed that at the end of 4 months patients in the endoscopic group $(96.3 \%)$ showed a complete relief of symptoms as compared to the curettage group $(74.1 \%)(\mathrm{p}<0.004)$. The persons who underwent endoscopy had lesser residual adenoid tissue post surgery as compared to the group that underwent conventional surgery. Regmi et al in his study showed that the mean volume of adenoid tissue that was removed via conventional curettage was $1.74 \pm 0.77 \mathrm{ml}$ (range $0.50-3$ ) as compared to $0.91 \pm 0.34 \mathrm{ml}$ (range 0.5-2) in endoscopic assisted adenoidectomy which is contrary to our findings in our study. ${ }^{3}$

The objective outcomes in these studies show that endoscopic assisted adenoidectomy technique was superior to curettage adenoidectomy in reducing adenoidal size post-surgery. ${ }^{12-14}$ Endoscopic coblation adenoidectomy ensured the complete removal of adenoids and reduced postoperative adenoid grade. It is also considered safer being under endoscopic control and easier access to the cranial portion of the adenoid and its intranasal extension. ${ }^{11,15}$

Post tonsillectomy also it has been observed that transient negative middle ear pressure occurs. These changes on the middle ear function occur in two stages: the first stage occurs in the immediate post surgical period. There is surgical trauma which leads to oedematous changes in the nasopharynx or may also cause obstruction in the lymphatic system which leads to changes in the mucosal capillary pressures of the middle ear due to swollen peritubal lymphatics leading to narrowing of the eustachian tubular access causing air absorption into the ear. ${ }^{4}$ Also damage to the soft palate during manipulation can cause partial laceration or hematoma and tension. This tension can indirectly lead to damage of the function of 'Tensor Veli Palatini' muscle which can affect the smooth coordination of the muscles which are needed for ventilation of the middle ear ${ }^{5}$. This could also affect deglutition and all these problems could lead to transient changes in the middle ear which returns back to normal once the inflammation reduces and lymphatic stasis subsides. ${ }^{4}$ These changes in middle ear pressure vary with the method of tonsillectomy but there aren't many studies to prove the same. ${ }^{2}$ Tympanometry is indirectly used to determine the middle ear pressure changes - both pre operatively and post operatively. Bonding and Tos in their study showed that in those undergoing cold steel dissection tonsillectomy $(60 \%)$ developed negative pressure $<100 \mathrm{~mm} \mathrm{H} 2 \mathrm{O}$ in the middle ear. ${ }^{16}$ They postulated could be due to postoperative edema in rhinopharynx and impairment of swallowing. Normalisation of middle ear pressure generally occurred within 3 days of operation in keeping with the rapid abatement of pain and postoperative edema in the pharynx in most patients after tonsillectomy. Hone et al in their study found that $39 \%$ of patients had a middle ear pressure less than $-99 \mathrm{daPa}$ at post tonsillectomy day one. ${ }^{17}$ In our study, the mean middle ear pressure (Table 2) was not statistically different either preoperatively or post operatively. In our study even though there was a reduction in middle ear pressures on postoperative day 7 and at 3 months it was not statistically significant. 


\section{CONCLUSION}

Endoscopic coblation technique is certainly more superior to curettage in terms of greater reduction in adenoid mass as seen in the present study. The effects on transient middle ear pressure between both groups showed no difference.

Funding: No funding sources

Conflict of interest: None declared

Ethical approval: The study was approved by the Institutional Ethics Committee

\section{REFERENCES}

1. Kaemingk KL, Pasvogel AE, Goodwin JL, Mulvaney SA, Martinez F, Enright PL, et al. Learning in children and sleep disordered breathing: findings of the Tucson Children's Assessment of Sleep Apnea (tuCASA) prospective cohort study. Journal of the International Neuropsychological Society. 2003;9(7):1016-26.

2. Benninger $\mathrm{M}$, Walner D. Coblation: improving outcomes for children following adenotonsillectomy. Clinical cornerstone. 2007;9(S13-23):1098-3597.

3. Regmi D, Mathur NN, Bhattarai M. Rigid endoscopic evaluation of conventional curettage adenoidectomy. J Laryngol Otol. 2011;125(1):53-8.

4. Holt GR, Watkins TM, Yoder MG, Garcia A. The effect of tonsillectomy on impedence audiometry. Otolaryngol Head Neck Surg. 1981:89:20-6.

5. Finkelstein Y, Tadmi Y, Zohan Y, Ruban Y, Laurian N. Can uvulopalatopharyngoplasty be harmful to the eustachian tube function? Acta Otolaryngol. 1987;104:511-20.

6. Clemens J, McMurray JS, Willging JP. Electrocautery versus curette adenoidectomy: comparison of postoperative results. Int J Pediatr Otorhinolaryngol. 1998;43(2):115-22.

7. Murat S, Canan A, Zehra Hilal A, Hamit A. Endoscopic-assisted versus curettage adenoidectomy: A prospective, randomized, doubleblind study with objective outcome measures. The Laryngoscope. 2010;120(9):1895-9.
8. Businco LDR, Angelone AM, Mattei A, Ventura L, Lauriello M. Paediatric adenoidectomy: endoscopic coblation technique compared to cold curettage. Acta Otorhinolaryngologica Italica. 2012;32(2):124.

9. Ozturk O, Polat S. Comparison of transoral powerassisted endoscopic adenoidectomy to curettage adenoidectomy. Advances in therapy. 2012;29(8):708-21.

10. El Tahan A, Elzayat S, Hegazy H. Adenoidectomy: comparison between the conventional curettage technique and the coblation technique in pediatric patients Original Article. Egyptian J Otolaryngol. 2016;32,152-5.

11. Feng Y, Yin S. Comparison of the powered-assisted adenoidectomy with adenoid curette adenoidectomy. J Clin Otorhinolaryngol. 2006;20(2):54-7.

12. Bradoo RA, Modi RR, Joshi AA, Wahane V. Comparison of Endoscopic-Assisted Adenoidectomy with Conventional Method. An Int J Clin Rhinol. 2011;4(2):75-8.

13. Nair BT, Nair VB. Coblation adenoidectomy our experience. Otolaryngol Online J. 2014;4:1-6.

14. Goel AK. Adenoidectomy: Conventional or Endoscopic Assisted? Clin Rhinol Int J. 2017;10(2):74-7.

15. Yang L, Shan Y, Wang S, Cai C, Zhang $\mathrm{H}$. Endoscopic assisted adenoidectomy versus conventional curettage adenoidectomy: a metaanalysis of randomized controlled trials. Springer Plus. 2016;5:426.

16. Bonding $\mathrm{P}$, Tos M. Middle ear pressure during brief pathological conditions of the nose and throat. Acta oto-laryngologica. 1981;92(1-6):63-9.

17. Hone S, Moodley S, Donnelly M, Fenton J, Gormley P, Walsh M. The effect of tonsillectomy on eustachian tube function. Clin Otolaryngol Allied Sci. 1997;22(6):511-4.

Cite this article as: Bhat SN, Dutta A. Evaluation of middle ear pressure and post-operative adenoid size in adenotonsillectomy: comparison between curettage and endoscopic assisted coblation technique. Int $\mathbf{J}$ Otorhinolaryngol Head Neck Surg 2019;5:670-4. 